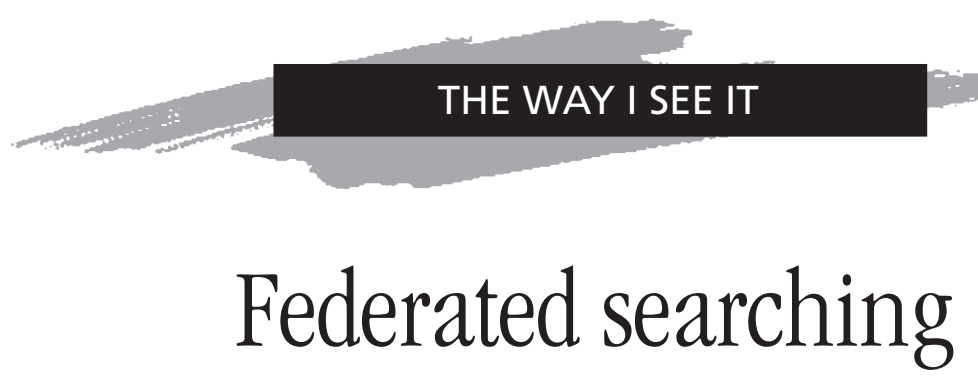

\title{
Friend or foe?
}

by William Baer

$\mathrm{W}^{\mathrm{n}}$

hat would be the ideal information retrieval system? Would it be similar to Star Trek, where the patron simply asks the computer a question and in a matter of moments receives the applicable information in the format needed? We have not arrived at this utopian version of research libraries, but we are closer than we were a few years ago. Technological advances have changed the way research is done. Online databases enable faster, more precise searching than their print counterparts. Many electronic databases provide patrons with access to full text of the articles from their homes or of ces.

Technology has advanced to the point that we can now offer federated searching to our patrons, which in some ways ts right in with the Star Trek model. There are advantages to searching multiple databases at one time, but there are also limitations. We should scrutinize both before deciding to move forward with this technology.

Can the concerns be alleviated without losing the bene ts? If not, do the bene ts outweigh the drawbacks? As one engineering professor used to tell me, Just because you can do something doesn $t$ mean you should.

\section{Friend}

There is de nitely an appeal to searching multiple databases simultaneously. We live in a fast-paced world, and one-stop searching promises to save time. Patrons will no longer have to repeat a search in each database. In fact, this time-saving feature might improve searching because students will nd articles from databases they otherwise may not have searched. Having a more complete search leads to more complete research and, hopefully, better results. Using one interface is less intimidating to many of our users. How many of us have heard complaints about having to learn three different interfaces to search three different databases?

Federated searching removes, or at least reduces, the number of decisions patrons need to make at the beginning of a search. Many students don t know which databases are best for the topics they are researching, but, by searching all of them at once, that need to know is reduced. Even our more knowledgeable patrons can serendipitously bene $\mathrm{t}$ from simultaneously searching many databases by uncovering articles from unexpected resources. For example, a colleague and I recently performed a federated search on Asperger syndrome. MEDLINE, ERIC,

About the author

William Baer is engineering librarian at Brigham Young University, e-mail: william_baer@byu.edu

(c) 2004 William Baer 
and Web of Science returned numerous results. What surprised us was nding an article in IEEEXplore. The article was extremely helpful, and we would not have found it without performing a federated search. The serendipitous aspect of federated searching will become increasingly bene cial as crossdisciplinary research increases.

\section{Foe}

Unfortunately, federated searching has as many potential problems as bene ts. When searching multiple databases at the same time, the quantity of articles searched increases, but the quality of the search is jeopardized. The federated search can $t$ use special features of any individual database that are not available on all of the databases. Searches are essentially reduced to the lowest common denominator. Actually, that isn t quite true. The truth is worse. A federated search engine will pass on the search to each database, but the individual databases interpret the search terms differently. Some databases support Boolean logic while some do not. Are two search terms entered next to each other interpreted as a phrase, or will and or or logic be used? Is the search limited to the title, abstract, descriptors, or full-text of the article? Each database interprets the search as it normally would, but the differences aren $t$ apparent.

Another problem is that federated searching tends to make evaluation of information more complicated. Students often have trouble recognizing scholarly literature. I often point out speci c databases that index only reputable journals or that allow limiting searches to peerreviewed articles. Evaluation becomes more dif cult when results from trade literature are mixed with ones from scholarly articles.

The one-stop searching mentality makes teaching good information-seeking habits harder. Students get the impression that they are searching everything, when in reality most federated searches search only a fraction of the databases that the library subscribes to. A patron might incorrectly assume that if a database isn $t$ bundled with the federated search, then it must not be very important. As librarians in higher education, we have a responsibility to teach students the information literacy skills they need now and in the future.

Does federated searching foster name recognition of the subject-speci c databases? Will our students know what individual databases to look for when they have moved beyond our walls? We hope so, but searching multiple databases at once might lessen students understanding of what they are searching.

The vision of searching all databases simultaneously adds another hurdle. We subscribe to many databases by purchasing a limited number of simultaneous users. Every time someone searches in one of those databases a seat is taken. If federated searching automatically includes these databases, the seats might be lled by searches on unrelated topics, not allowing access to researchers who need it.

\section{Conclusion}

Despite the long list of possible pitfalls, I am not against federated searching. Actually, I am excited by the prospect, but great care must be taken in selecting a federated searching product. If we don $t$ recognize the hurdles of the new technology, we re liable to be tripped by them as we run to keep up with our patrons information needs. We need to realize that federated searching is another tool we can use to meet our patrons informational needs. However, it does not eliminate the need for access to databases individually.

I hope that someday technology will overcome all of the concerns related to federated searching. Until then, libraries should move forward cautiously. Thoughtfully select the features that are most critical to the students and faculty of your institution. Then select the federated searching service that best meets those needs. Highly customizable federated searching software can overcome many of the problems. As the future unfolds, federated searching will help us provide better service. 